\title{
DIREITO E DEMOCRACIA SOB ENFOQUE DA FILOSOFIA POLÍTICA DE DELEUZE E GUATTARI: QUESTIONAMENTOS E POSSIBILIDADES
}

\section{LAW, DEMOCRACY AND DELEUZE/GUATTARI'S POLITICAL PHILOSOPHY: QUESTIONS AND POSSIBILITIES}

\author{
Leonardo Monteiro Crespo de Almeida \\ Universidade Federal de Pernambuco - UFPE - (Recife, PE, Brasil)
}

Recebimento: 16 fev. 2018

Aceitação: 11 abr. 2018

\begin{abstract}
Como citar este artigo / How to cite this article (informe a data atual de acesso / inform the current date of access):
\end{abstract}
ALMEIDA, Leonardo Monteiro Crespo de. Direito e democracia sob enfoque da filosofia política de Deleuze e Guattari: questionamentos e possibilidades. Revista da Faculdade de Direito UFPR, Curitiba, PR, Brasil, v. 63, n. 2, p. 39-58, ago. 2018. ISSN 2236-7284. Disponível em: <https://revistas.ufpr.br/direito/article/view/57920>. Acesso em: 30 ago. 2018. DOI: http://dx.doi.org/10.5380/rfdufpr.v63i2.57920.

\section{RESUMO}

O objetivo deste artigo consiste em esclarecer uma possível abertura, no âmbito da filosofia política de Gilles Deleuze e Félix Guattari, para uma reflexão teórica sobre direito e democracia. Um problema inicial, apontado por Philippe Mengue, é que a filosofia política dos autores introduz severas restrições ao conceito de democracia e permanece omissa em torno dos direitos. Tomando como ponto de partida as ressalvas feitas por Mengue em torno da aversão deleuzeana ao democrático, o artigo pretende mostrar que Mengue ignora certas potencialidades da filosofia deleuzeana que permitiriam repensar essas noções. A fundamentação do posicionamento deste artigo se encontra majoritariamente ancorada na literatura secundária, especialmente nas leituras de Paul Patton sobre o tema, e também no conjunto de textos de Deleuze e Guattari, especialmente em O Que é a Filosofia e nos Mil Platôs. A pesquisa sustenta que direito e democracia podem ser articulados na filosofia dos autores mediante uma perspectiva sobre o político atrelado à imanência e à construção conceitual de novas formas de vida do social.

\section{PALAVRAS-CHAVE}

Deleuze. Guattari. Direito. Democracia.

\begin{abstract}
This article intends to develop a possible opening within the political philosophy of Gilles Deleuze and Felix Guattari to make possible a theoretical reflection on law and democracy. As mentioned by Philippe Mengue, an initial problem is that the political philosophy proposed by the authors makes quite averse remarks on democracy and does not express an interest on the legal realm. Taking as our starting point the questions articulated by Mengue regarding a possible incompatibility between Deleuze/Guattari philosophy and democracy, the article points out that Mengue ignores a few potentialities inscribed in that philosophy that would allow us to rethink law and democracy within the political assumptions and concepts of Deleuze and Guattari's philosophy. The interpretation presented by this research is directly influenced by the reading of a few Deleuze scholars, such as Paul Patton, and the works of Deleuze and Guattari themselves, Qu'est-ce que la philosophie? and
\end{abstract}


Mille Plateaux. This article sustains that there is room to think law and democracy from the perspective of the authors when one thinks the political as immanent and guided by conceptual construction of new forms of social life.

\section{KEYWORDS}

Deleuze. Guattari. Law. Democracy.

\section{INTRODUÇÃO}

A democracia tem uma abordagem ambivalente na obra de Gilles Deleuze e de Félix Guattari. De início, os autores se esforçam em se manter distantes de uma concepção liberal da democracia que estaria comprometida com a manutenção e o fortalecimento dos sistemas capitalistas contemporâneos. Semelhante noção, principalmente quando revestida de uma conotação procedimental, pouco teria de relevante para que se possa pensar transformações políticas radicais na sociedade, uma das preocupações presentes no pensamento de Deleuze e Guattari.

Mas não existiriam outros potenciais inscritos no conceito de democracia que não foram ou mesmo não poderiam ser - atualizados tendo como base a concepção mencionada? Se, na obra $O$ Que é a Filosofia, os autores ressaltam como os conceitos filosóficos ultrapassam os seus contextos históricos originais para operarem intervenções em cenários muitos distintos daqueles, quais outras perspectivas a filosofia política de Deleuze e Guattari poderia trazer para se pensar uma noção de democracia situada para além das preocupações institucionais que a situam como forma de governo?

A pretensão deste artigo consiste em pensar o conceito de democracia na obra dos autores com o intuito de afastar a sua submissão aos axiomas do capitalismo globalizado e aos seus imperativos econômicos, como os autores parecem fazer em Mil Platôs e também em $O$ Que é a Filosofia. O primeiro problema dessa abordagem é que, ao subordinar as múltiplas formas de governo ao capitalismo global, a distinção entre nações marcadas por governos autoritários e democráticos se torna pouco significativa, já que, de alguma maneira, ambas as formas de governo se encontram submetidas aos axiomas do capitalismo. Ainda que não se venha a alimentar quaisquer preocupações normativas, as diferenças entre as duas formações de Estado existem e são relevantes para problematizar o exercício do poder político e as suas formas de resistência.

O segundo problema reside em assimilar o político ao econômico mediante a subsunção do conceito de democracia ao de capitalismo. Se, por um lado, a democracia representa uma forma de governo usual das nações capitalistas de primeiro mundo, por outro ela não é imprescindível para a sua implementação, a exemplo dos países capitalistas que não a adotam como forma de governo. 
Faltaria destacar as múltiplas possibilidades de associação e inserção do conceito de democracia que não passariam pelo seu entrelaçamento com o capitalismo.

Uma possibilidade de leitura da filosofia política dos autores consiste em destacar e desenvolver a contraposição entre democracia e Estado, para com isso responder, mesmo que sucintamente, às três indagações estabelecidas. O propósito deste trabalho não consiste em trazer a filosofia política de Deleuze e Guattari para perto das teorias da democracia elaboradas por autores como, entre outros, John Rawls, Michael Walzer e Jürgen Habermas, mas apontar o compromisso dos dois autores com certos valores associados a essa tradição e seu impacto para a reflexão proposta por este trabalho em torno das práticas políticas e da criação dos direitos.

Em termos metodológicos, o artigo estabelece como ponto de partida a leitura de Philippe Mengue em torno dessa problemática e as razões levantadas pelo autor para ressaltar um distanciamento entre a filosofia deleuzeana e a democracia. A leitura de Mengue propõe considerações em torno das restrições levantadas pelos autores em suas obras, mas também faz ressalvas que podem abrir espaço para outras possibilidades de leitura nem sempre aparente nas linhas de reflexão sustentadas por Deleuze e Guattari. Considerando que algumas das posições são específicas de Deleuze, e outras envolvem as obras escritas em colaboração com Guattari, algumas vezes será mencionado tão somente Deleuze para apontar uma posição presente em suas obras particulares. Deleuze e Guattari serão mencionados juntos toda vez que as posições estiverem presentes nas obras escritas em colaboração.

O trabalho recorre às obras de Paul Patton com o intuito de mostrar os caminhos que permitem repensar o liame entre direito, democracia e vida nos trabalhos dos autores. Tanto Paul Patton quanto Alexandre Lefebvre chamam atenção para uma latente preocupação deleuzeana em torno dos direitos, e também com certas características abrangentes que aproximam a reflexão filosófica do autor sobre o imaginário político inscrito na democracia.

A hipótese de interpretação proposta por este estudo consiste em repensar Estado de direito e democracia como um potencial político imanente a essas sociedades e que se desenvolve a partir de um quadro de problemas mais amplo, associado à pergunta pela normatividade na filosofia desses autores. Em que medida a obra desses filósofos fornece critérios ou elementos que visem criticar e confrontar regimes políticos autoritários? Essa será a pergunta que vai nortear a leitura presente no artigo e à qual ele pretende responder. 


\section{SITUANDO O PROBLEMA: A APARENTE AVERSÃO À DEMOCRACIA}

Em sua resposta crítica à leitura de Philippe Mengue sobre a dificuldade, senão mesmo inviabilidade, de um acolhimento da democracia pela filosofia de Deleuze, Patton observa que, muito embora se possa situar o autor como um teórico da democracia, ainda assim existe em sua obra um comprometimento aos chamados valores democráticos. O raciocínio é o seguinte: se Deleuze não elaborou uma teoria normativa da democracia, portanto, uma que permitisse distinguir formas democráticas de governo daquelas que não o são, ainda assim se encontram elementos em sua obra que permitem situá-la dentro de um imaginário político democrático. O que Patton ressalta é o comprometimento deleuzeano com o pluralismo, a liberdade e a igualdade, como também com uma permanente fiscalização sobre o poder político estabelecido.

Central para a tese de Mengue de que existiria uma disposição hostil entre Deleuze e a democracia é a conjuntura histórica e política de maio de 68, pano de fundo para o projeto capitalismo e esquizofrenia, desenvolvido em colaboração com Félix Guattari. O significante “democracia” seria indissociável da manutenção de um projeto político burguês cuja finalidade central não seria outra que não a implementação e fortalecimento do capitalismo global (MENGUE, 2003, p. 43).

Embora Mengue observe uma paridade existente entre os pressupostos ontológicos da filosofia deleuzeana e o regime democrático, três noções do seu pensamento terminariam por justificar a mencionada hostilidade deleuzeana à democracia: imanência, devir, minoridade. Em que uma predileção pela imanência em vez da transcendência levaria a uma rejeição política da democracia?

De início, em vez de respaldar uma hostilidade, a preferência pela imanência levaria a uma compatibilidade entre o que propõe Deleuze e a prática da democracia (OLIVIER, 2014, p. 3 et seq.): o principal referencial da democracia são as suas próprias práticas constitutivas que continuamente redefinem direitos, normas e formas de participação. É próprio do democrático, então, esse autoconfrontamento e transformação a partir de sua dinâmica interna. Como observa Claire Colebrook, a imanência, em Deleuze, está diretamente associada à gênese e à emergência (COLEBROOK, 2009, p. 12). Neste sentido, a democracia não tem relação, nem precisa fazer alusão, a qualquer princípio imutável (e, por isso mesmo, metafísico) que lhe seja transcendente. Não haveria, ao menos neste ponto, qualquer incompatibilidade com a ideia de imanência preterida por Deleuze, nem mesmo uma associação necessária com o fortalecimento do capitalismo.

Os elementos que Mengue suscita para defender a sua posição recaem em alguns comentários negativos feitos por Deleuze na década de setenta e que tinham como alvo duas noções 
centrais para as principais reflexões contemporâneas sobre a democracia: direitos humanos e o Estado de Direito. Escreve o autor:

Nós estamos retornando às queixas de Benda que colocavam Bergson como um traidor de sua própria classe, a classe clerical, ao pensar o movimento. Nos dias atuais são os direitos dos homens que nos fornecem os valores eternos. É o Estado constitucional (État de Droit) e outras noções que todos reconhecem como sendo muito abstratas. E é em nome de tudo isso que o pensamento é obstruído e que qualquer análise em termos de movimentos se encontra bloqueada (DELEUZE, 1995, p. 121-122, tradução nossa) ${ }^{1}$.

O grande problema apontado por Deleuze na passagem acima - e parece ser algo que escapa à análise de Mengue - não reside nos conceitos de direitos humanos e de Estado de Direito, e sim na maneira como supostamente essas duas noções acabam impedindo que se pense o movimento. Uma análise superficial das breves considerações feitas por Deleuze acerca da relação entre lei/jurisprudência serve para reiterar que é importante situar a preocupação do autor em torno da suposta transcendência que propõe essas noções em detrimento de alguma preocupação de ordem institucional e ontológica (MENGUE, 2003, p. 57 et seq.).

Para além da relação com o movimento, é na obra O Que é a Filosofia que Deleuze e Guattari vislumbram uma forte associação entre a forma política democrática e a promoção do capitalismo. Embora não tenham desenvolvido muito as razões que os levaram a sustentar essa associação, podese vê-la como mais um efeito decorrente da percepção usual da democracia presente no contexto de maio de 68.

Acrescente-se a isso toda a estratégia estadunidense na difusão global da democracia, com a consequente formação de novos mercados, e se faz presente um panorama marcado por desconfianças em torno do potencial socialmente transformador das democracias liberais. A difusão e consequente hegemonia global do modelo democrático surge como suporte institucional para a promoção do capitalismo e mesmo de formas variadas de intervenção, dos países economicamente desenvolvidos naqueles cujas economias permanecem frágeis e dependentes.

Embora seja sustentável supor que Deleuze estivesse, de fato, ressaltando que os conceitos de Estado de Direito e Direitos Humanos estariam indissociavelmente associados com a transcendência e com isso constituindo obstáculos ao pensamento político ancorado no movimento, existem outras leituras que permitem formas de problematização mais sofisticadas. Para tanto,

\footnotetext{
${ }^{1}$ No original: "We're back to Benda complaining that Bergson was a traitor to his own class, the clerical class, in trying to think motion. These days it's the rights of man that provide our eternal values. It's the constitutional state (État de droit) and other notions that everyone recognizes as very abstract. And it's in the name of all this that thinking is fettered and that any analysis in terms of movements is blocked”.
} 
necessita-se mapear os problemas elencados, de modo a desenvolver estratégias analíticas a fim de superá-los - ou mitigá-los - na abordagem da obra de Deleuze/Guattari aqui proposta.

O primeiro problema consiste na associação entre a promoção da democracia e o fortalecimento do capitalismo. O segundo está ligado à obstrução do pensamento comprometido com o movimento, que os dois autores defendem, de relação que a democracia, Estado de Direito e direitos humanos guardam com a transcendência. O terceiro problema consiste na manipulação dos direitos humanos para fins do fortalecimento de certas nações em vez de concretizar a finalidade radical e emancipadora que se encontraria na gênese desses direitos. São esses os dois principais eixos em que Philippe Mengue constrói os seus argumentos contra uma compatibilidade das filosofias de Deleuze e Deleuze/Guattari à democracia. O trabalho irá agora examiná-los.

\section{A DISTINÇÃO ENTRE O CONCEITO E OS DISCURSOS QUE LHE TOMAM COMO REFERÊNCIA}

Para se lidar com o primeiro problema suscitado, uma pergunta preliminar será a seguinte: ao demonstrar a sua aversão à democracia, principalmente quando aponta a sua relação com a promoção do capitalismo, Deleuze estaria focando no potencial e na constituição do conceito de democracia? Alexandre Lefebvre (2012, p. 48-49) desenvolve questionamento semelhante no que se refere aos comentários de Deleuze aos direitos humanos. Precisa-se ter cuidado para não subsumir um conceito e as possibilidades que ele traz consigo aos discursos que visam sua instrumentalização para fins específicos.

Um determinado discurso de promoção da democracia opera um recorte nos elementos comumente associados ao conceito, seccionando e enfatizando as partes que lhe são importantes, ampliando ou reduzindo a sua extensão. A identificação entre discurso e conceito implica também subsumir os diferentes potenciais que se abrem e se deslocam a partir de sua história, sempre particular, às várias práticas estratégicas das formações discursivas. A promoção internacional da democracia realizada por determinadas potências ocidentais não pode assimilar todo o potencial, cuja totalidade permanecerá sempre inexplorada: a da democracia.

Essa distinção é importante para que se possa mapear a extensão e o direcionamento das restrições que Deleuze levantará contra a democracia. Embora nenhuma dessas restrições seja rigorosamente desenvolvida pelo filósofo francês, observou-se que será a partir delas que Philippe Mengue identificará uma incompatibilidade com a democracia, ainda que, tomando como referência 
a metafísica subjacente à filosofia deleuzeana, a própria incompatibilidade seja questionável, conforme mencionado (MENGUE, 2003, p. 57 et seq.).

Uma hipótese de leitura consiste em observar que o centro do questionamento dos autores reside em uma compreensão administrativa da política democrática que pode facilmente vir a ser identificada com a democracia. Pode-se caracterizar o sentido mais amplo dessa compreensão como aquela em que a participação popular, no horizonte de um Estado democrático, esgota-se nos vários mecanismos que sustentam a representação indireta, a exemplo dos procedimentos eleitorais. Fora isso o que existe é um fosso entre o aparato burocrático do Estado, cujas decisões impopulares são muitas vezes fundamentadas em "razões técnicas" que escapam a uma "prestação de contas” à população, e os múltiplos espaços sociais tomados como objeto de administração da política. O vínculo entre controle e democracia se mostra central para a perspectiva de Deleuze e Guattari. Em O Que é a Filosofia, os autores problematizam explicitamente o conceito de democracia ao escreverem:

\begin{abstract}
Quem exceto a polícia e as forças armadas que coexistem com as democracias pode controlar e administrar a pobreza e a desterritorialização-reterritorialização das favelas? Qual socialdemocracia se recusou a atirar quando os pobres saíram dos seus territórios ou guetos? Direitos não salvam nem seres humanos nem a filosofia reterritorializada no Estado democrático (DELEUZE; GUATTARI, 1994, p. 107, tradução nossa)².
\end{abstract}

Um ponto que logo se sobressai na passagem é o de que as democracias tomadas como objeto são aquelas empiricamente situadas, casos particulares, em vez do próprio conceito em si mesmo. É sobre elas que o vínculo com o controle e com a administração da violência será estabelecido. É uma perspectiva que, embora distinta, permanece próxima daquela que será sustentada por Jacques Rancière quando estabelece a distinção entre política e polícia (RANCIÈRE, 1999, p. 21 et seq.). Conforme este autor, o que normalmente se situa como constituindo o espaço da política é, na verdade, a dinâmica dos mecanismos voltados para a administração da população.

Uma vez articulado nesses termos torna-se plausível dizer que a condenação dos autores recai nos discursos que pretendem promover a democracia como única possibilidade política para lidar com os efeitos colaterais associados ao desenvolvimento econômico das sociedades capitalistas. A queda do Muro de Berlim sinalizaria para uma vitória irrestrita das democracias liberais ante qualquer alternativa político-econômica: o futuro histórico, antes aberto às múltiplas experiências políticas, é agora ponderado a partir das configurações políticas do presente. Se a polícia é o recurso

\footnotetext{
${ }^{2}$ No original: "Who but the police and armed forces that coexist with democracies can control and manage poverty and the deterritorialization-reterritorialization of shanty towns? What social democracy has not given the order to fire when the poor come out of their territory or ghetto? Rights save neither men nor a philosophy that is reterritorialized on the democratic State”.
} 
estatal empregado para a administração da pobreza, a representação popular presente nessas democracias é ancorada também na segmentação econômica do social.

A presente pesquisa considera, portanto, que as objeções levantadas pelos autores não se referem ao conceito de democracia, mas à maneira como ele é retomado de modo a bloquear experimentações políticas distintas a partir de uma concepção administrativa da própria política sempre atrelada ao desenvolvimento do capitalismo. Em síntese, por mais diversos que sejam os desenhos institucionais e as suas dinâmicas nas diferentes configurações de política, as diferentes modalidades de Estado seriam iguais ante o mercado mundial:

Agora, modelos de realização podem ser bastante diversos (democrático, ditatorial, totalitário), sendo sim verdadeiramente heterogêneos, mas ainda assim são isomórficos em relação ao mercado mundial uma vez que este não apenas pressupõe mas também produz desigualdades de desenvolvimento. É por isso que, como já foi muito observado, os Estados democráticos estão tão ligados, e até mesmo comprometidos, pelos Estados ditatoriais a ponto de a defesa dos direitos humanos precisar surgir como crítica interna de cada democracia (DELEUZE; GUATTARI, 1994, p. 106, tradução nossa) ${ }^{3}$.

O mercado mundial une e propõe alianças entre democracias discursivamente comprometidas com a proteção dos direitos humanos e tiranias que desrespeitam esses mesmos direitos com a intensidade e insistência que as primeiras os promovem. Com isso, os autores não estão apenas equiparando um Estado democrático com um Estado ditatorial, mas ressaltando a maneira como ambas as formações tendem a se entrelaçar no que diz respeito aos imperativos do mercado global. Com essa linha de argumentação o que os autores pretendem é chamar atenção para o que, no contexto do capitalismo globalizado, não é a forma democrática, nem a estrutura normativa supranacional dos direitos humanos, que são universais, mas o mercado.

A desconfiança referente à promoção da democracia e dos direitos humanos, nesse contexto, é pensada lado a lado com as limitações implícitas desses discursos, a saber, a dificuldade em situar a interferência e o peso dos imperativos do mercado ante as múltiplas formas de estabelecimento dessas noções. Do mesmo modo que, como os autores mencionam, os Estados democráticos tenderiam a uma compartimentalização administrativa da pobreza, acrescente-se as diversas possibilidades em que os direitos humanos seriam instrumentalizados para atenderem aos objetivos econômicos das potências mundiais.

\footnotetext{
${ }^{3}$ No original: "Now, models of realization may be very diverse (democratic, dictatorial, totalitarian), they may be really heterogeneous, but they are nonetheless isomorphous with regard to the world market insofar as the latter not only presupposes but produces determinate inequalities of development. That is why, as has often been noted, democratic States are so bound up with, and compromised by, dictatorial States that the defense of human rights must necessarily take up the internal criticism of every democracy”.
} 
Uma situação ilustrativa seria a intervenção das forças da OTAN no Kosovo e os dilemas que surgem a partir dessa situação. Supondo que, hipoteticamente, o Conselho de segurança da ONU se mostrasse ausente quanto a um mandato que autorizaria a intervenção por questões humanitárias, seria possível ainda assim realizar essa intervenção em nome dos direitos humanos e dos que se encontram oprimidos? Por um lado, há a necessidade de se preservar o balanço nas relações supranacionais por meio do direito internacional, o que, em contrapartida, permitiria a ausência de punição referente às infrações aos direitos humanos; pelo outro, há a autorização de intervenções humanitárias que podem promover um severo desequilíbrio nas relações supranacionais.

Em seu artigo Violence in the name of human rights, Simon Chesterman observa como esse dilema não foi sequer levantado no tocante ao conflito interno por que passou Ruanda em 1994. O autor escreve:

\begin{abstract}
O problema, no entanto, é que este não foi o dilema encarado no contexto de Ruanda. Em vez do direito internacional impedindo que os Estados viessem a tomar partido na defesa da população Tutsi, o problema em 1994 foi que nenhum Estado se dispôs a intervir. Quando a França, dificilmente um ator desinteressado, optou por intervir, a sua decisão foi rapidamente aprovada em uma resolução do Conselho (embora referências à ‘imparcialidade’, um prazo de dois meses e cinco abstenções tenham sugerido uma apreensão referente às motivações da França) (CHASTERMAN, 2012, p. 134, tradução nossa) ${ }^{4}$.
\end{abstract}

Da mesma maneira que Deleuze e Guattari apontam a intervenção dos interesses do mercado na maneira com que as democracias liberais lidam com as diferenças de classe, também se encontra essa intervenção - e as suas consequências ambivalentes - no contexto das relações internacionais fundamentadas a partir dos direitos humanos. Em ambos os casos, o risco da promoção tanto pela democracia quanto pelos direitos humanos consiste em perder de vista toda a ambivalência que existe por trás e ao redor de duas noções com potenciais radicais de transformação, mas que podem também acabar promovendo a conservação e a fixação das situações.

É nisso que se encontra a mencionada ambivalência: noções que pretendem transformar e desestabilizar o status quo podem também se tornar fundamentais para conter e estabilizar possíveis tensões que promoveriam mudanças significativas. Embora Deleuze, e também Guattari, não desenvolvam explicitamente essa linha de argumentação nas páginas de O Que é a Filosofia, as passagens em que se mostram reticentes quanto aos conceitos de democracia e direitos humanos apontam uma certa abstração que permitiria que as duas noções fossem manipuladas. Ainda que não

\footnotetext{
${ }^{4}$ No original: "The problem, however, is that this was not the dilemma faced in the context of Rwanda. Rather than international law restraining a state from acting in defense of the Tutsi population, the problem in 1994 was that no state wanted to intervene at all. When France, hardly a disinterested actor, decided to intervene, its decision was swiftly approved in a Council resolution (though reference to 'impartiality', a two-month time-limit and five abstentions suggested wariness about France's motivation)".
} 
tenham operado a distinção aqui discutida, a saber, entre conceitos e os discursos políticos que os promovem, o tipo de questionamento suscitado pelos autores reflete mais as limitações e fragilidades dos discursos de promoção do que o potencial dos dois conceitos aqui discutidos.

\section{REPENSANDO O CONCEITO DE DEMOCRACIA A PARTIR DA IMANÊNCIA}

Em um dos trechos das suas entrevistas, mencionado por Philippe Mengue e outros leitores que examinam a filosofia política do autor, Deleuze estabelece uma associação entre democracia, direitos e transcendência para, em seguida, contrapor com a relação entre jurisprudência e imanência. Essa contraposição entre transcendência/imanência serve ao filósofo para que possa delimitar o objeto de seu interesse tendo como referência os pressupostos metafísicos que o seu projeto informa.

Na citação abaixo os autores associam distinção entre imanência e transcendência para fazer uma análise sucinta das noções de Estado constitucional e também da própria formação do Direito. Jurisprudência e singularidade são articuladas na seguinte exposição de Deleuze:

E nos Estados constitucionais, não são os direitos constitucionais codificados e estabelecidos
que são pertinentes e sim tudo aquilo que é juridicamente problemático e que constantemente
ameaça trazer à tona o questionamento daquilo que se encontra estabelecido. Não existe
atualmente escassez de problemas desse tipo; o Código Civil tem sido torcido ao ponto de
ruptura e tanto o Código Penal quanto o sistema prisional estão uma grande bagunça. Direitos
não são criados por códigos e pronunciamentos, mas pela jurisprudência. A jurisprudência é
que é a verdadeira filosofia do direito, lidando com singularidades e se desdobrando a partir
delas (DELEUZE, 1995, p. 153, tradução nossa) ${ }^{5}$.

Se a criação dos direitos ocorre por meio da jurisprudência, isso se dá por conta de sua inserção em um campo de problemas que se materializa nos vários casos concretizados trazidos à apreciação do Judiciário. As especificidades dos problemas trazidos por esses casos podem deslocar - ou pôr em questão - elementos jurídicos consensualmente estabelecidos.

Se Deleuze opera um corte entre a estrutura normativa do direito e a maneira como essa estrutura é mobilizada na resolução, sempre contextual, dos problemas particulares, assim o faz para enfatizar a dimensão do encontro e da construção conceitual (COLEBROOK, 2009, p. 12-13). É no encontro entre o problema trazido pelo caso e o contexto em que, uma vez ponderadas as questões trazidas pelo caso, deve-se enunciar o direito, que a jurisprudência explorará o plano das virtualidades a partir do atual.

\footnotetext{
${ }^{5}$ No original: “And in constitutional states, it's not established and codified constitutional rights that count but everything that's legally problematic and constantly threatens to bring what's been established back into question that counts. There's not shortage of such problems these days; the whole Civil Code's strained to breaking-point, and the Penal Code is in a great mess as the prison system. Rights aren't created by codes and pronouncements but by jurisprudence. Jurisprudence is the philosophy of law, and deals with singularities, it advances by working out from singularities".
} 
Problemas jurídicos podem ser concebidos como questões à espera de soluções que venham a dissolvê-las mediante a implementação de um curso de ação institucionalizado: esse seria o entendimento corriqueiro. Entretanto, englobam também cartografias e linhas de fuga capazes de possibilitar a reformulação das categorias jurídicas estabelecidas como também o surgimento de outras tantas. Por isso se torna limitador subsumir o direito a um elemento que se sobrepõe - e visaria até a antecipar - ao encontro, a exemplo da norma jurídica positiva. Esta tomaria parte no engajamento com os problemas por meio do encontro, mas não se sobrepõe nem ao caso, como ocorreria mediante uma operação subsuntiva, não ao problema, como se a norma já trouxesse as possibilidades para o seu desdobramento (LEFEBVRE, 2008, p. 213 et seq.).

O que seria estável e contínuo na prática do direito não se encontra situado na ordem da permanência e do imutável, mas da resistência e captura - sempre precária - do devir. Patton ressalta este ponto:

A sua preferência pela jurisprudência em detrimento das declarações sobre os direitos humanos ou o seu confinamento em códigos jurídicos reflete uma preferência pelo processo criativo contínuo e aberto que leva à modificação das leis existentes e também à invenção de novos direitos (PATTON, 2005, p. 405, tradução nossa) ${ }^{6}$.

O problemático em se pensar o novo reside nos elementos de transcendência que integram a reflexão teórica sobre o direito. Em vez de pensá-lo a partir de cartografias de forças que o moldam e distorcem, ele é concebido sempre mediante suposições e conceitos que supostamente escapariam a esse devir, constituindo assim a sua essência no sentido de fixar aquilo que lhe seria o mais próprio: a norma jurídica, a decisão soberana, a justiça, os direitos naturais, etc. Em vez de emergirem a partir de problemas contextualmente situados, essas noções se prendem ao universal e ao geral abstrato que almejam organizar a prática do direito a partir de elementos que a transcendem.

Linha de argumentação semelhante pode ser transposta para o conceito de democracia. Se concebida como uma forma geral de organização do político, a noção tende a refletir uma captura e organização dos processos políticos que cortam os vários planos das relações sociais. Continuaria a atuar como uma noção transcendente sobreposta às tensões que estruturam o político, neste ponto compreendido como o fundamento ontológico do social.

Essa posição estaria longe de mapear o potencial presente no conceito de democracia, especialmente no tocante a uma concepção imanente. Mesmo as perspectivas consideradas mais sólidas e que gozam de ampla aceitação pela maioria da população, em um contexto democrático,

\footnotetext{
${ }^{6}$ No original: "His preference for jurisprudence over declarations of human rights or their enshrinement in legal codes is a preference for the ongoing and open-ended creative process that leads to the modification of existing laws and the invention of new rights”.
} 
podem ser devidamente contestadas. Instituições, crenças e opiniões estão todas abertas a transformações inusitadas e contingentes que se desdobram a partir das circunstâncias sociais nas quais elas se encontram inseridas.

Conceber a democracia enquanto conceito que situa a política em termos imanentes significa insistir não apenas nessa abertura, mas em seu devir interno que promove as mais diversas formas de criação, inclusive modificando de maneira sucessiva e persistente as maneiras pelas quais o poder político institucionalizado pode ser exercido, a exemplo dos direitos fundamentais e de todo um aparato constitucional voltado para a restrição do poder soberano. Neste ponto é importante a introdução de dois conceitos muito importantes na filosofia de Deleuze e Guattari que integram a sua ontologia dual: o par virtual e atual (PATTON, 2010, p. 131 et seq.).

Os autores operam um contraste entre dois planos distintos e entrelaçados: um é voltado para o atual, portanto, para as coisas e os vários estados de coisas habituais, inscrito na história, enquanto o outro, concebido em termos de virtualidades, é preenchido pelos devires e eventos puros, sendo ahistórico. Neste último plano se encontram também dois tipos de processos: processos de desterritorialização, que levam adiante as várias formas de metamorfoses, e processos de captura e contenção, nomeados também de processos de reterritorialização. Deleuze e Guattari escrevem:

O Estado como aparelho de captura tem uma potência de apropriação; mas, justamente, essa potência não consiste somente em que ele captura tudo o que pode, tudo o que é possível, sobre uma matéria definida como phylum. O aparelho de captura se apropria igualmente da máquina de guerra, dos instrumentos de polarização, dos mecanismos de antecipaçãoconjuração (DELEUZE; GUATTARI, 2008, p. 128, grifo do autor).

Cada evento integra esses dois planos e processos: ao mesmo tempo que se encontra inserido em um contexto historicamente situado, ele também integra o plano a-histórico das virtualidades e devires que, por sua vez, é atualizado no primeiro plano. O importante é que a virtualidade de um evento jamais poderá ser reduzida ou limitada pelas formas variadas de sua atualização. Sendo assim, as atuais democracias não esgotam, nem sequer estabelecem os limites, para a virtualidade que se encontra inscrita nesse conceito. O que se tem são contínuos processos de sobrecodificação em vez de esgotamento (DELEUZE; GUATTARI, 2004, p. 99).

As transformações que se sucedem no plano histórico alteram e abrem espaço para novos devires e conexões estabelecidas no plano das virtualidades que, por sua vez, reterritorializam o plano atual. A conexão entre esses dois planos abre espaço para relações inusitadas que escapam a um mapeamento pré-estabelecido. Essa dupla perspectiva que agora recai sobre a democracia - evento que se desdobra a partir da história e processo que se atualiza em formações sociopolíticas específicas, sem jamais se reduzir a elas - ajuda a compreender também a sua rejeição à democracia e aos direitos 
humanos. O motivo é o mesmo: a fundamentação dos direitos humanos, e por tabela também da democracia, não precisa ser ancorada em alguma característica transcendente tanto do ser humano quanto da formação social.

O problema da fundamentação desses direitos reside na abstração que os reveste: a humanidade, entendida enquanto aspecto essencial e distintivo do ser humano, é desarticulada de qualquer forma de devir (LEFEBVRE, 2012, p. 50 et seq.). A soberania popular, responsável por fundamentar as práticas democráticas, existe somente a partir da abstração que se faz ante as múltiplas formas de segmentação do social. Não importa quais sejam as modificações subjacentes aos segmentos, a soberania popular se mantém como fonte de respaldo do exercício do poder político democrático, ainda que apenas uma pequena parcela possa vir a expressar as suas considerações e questionamentos. Quais são os sentidos de maioria e minoria no contexto da dinâmica política, em especial aqueles que caracterizariam a democracia? Que relação existiria entre essas noções?

Quando discutem essas noções no decorrer do projeto Capitalismo e Esquizofrenia, Deleuze e Guattari situam os espaços de devir mediante uma contraposição entre os focos de poder e captura - o majoritário - e o que o opõe - o ‘minoritário’. A distinção entre os dois não se encontra fundada em uma observação quantitativa: o majoritário se impõe como padrão, standard, o qual vai medir, organizar e sujeitar tudo que dele se distancia (DELEUZE; GUATTARI, 2004, p. 90 et seq.).

O minoritário, por sua vez, refere-se ao potencial de grupos e indivíduos de se desviarem desses padrões. Enquanto o majoritário pode ser quantificado e demarcado, o minoritário é elusivo, escapa, não pode ser mapeado. Por isso, além do par majoritário/minoritário, Deleuze e Guattari insistem no devir-minoritário como movimento que escapa à tendência normalizadora do majoritário, permitindo a exploração da virtualidade dos acontecimentos e de novas experimentações que transformam as demarcações estabelecidas pela mencionada tendência.

Os direitos constituem um dos instrumentos que permitem a manutenção e a proteção das formas de vida ante a intervenção do Estado e dos demais. Neles se encontram um duplo risco: a proteção da segurança social acompanhada pela destituição jurídica do indivíduo ou segurança deste ante a intervenção do Estado e/ou de um terceiro. Direitos surgem e se desenvolvem por meio de relações com outros direitos, estabelecendo limites e justificando formas de ação e omissão no espaço social (COLEBROOK, 2015, p. 156).

A construção de novos direitos implica também o advento de novas possibilidades de intervenção nos múltiplos espaços institucionais integrantes da constituição das sociedades modernas (PATTON, 2010, p. 185 et seq.). Se, por um lado, permitem a assimilação de uma forma de vida rechaçada a partir de uma estrutura normativa estabelecida, por outro podem ser instrumentalizados 
enquanto proteção e barreira contra movimentos que ameacem a própria existência dessa mesma forma de vida.

Há uma certa tensão entre a transformação incessante do social e o enquadramento normativo, logo controlador, que o aparato jurídico pretende sobrepor às mudanças. Ao mesmo tempo que se reestrutura em função da dinâmica do social, o direito, sob uma perspectiva estritamente institucional, almeja modular e intervir nesse domínio por meio de conceitos desenvolvidos a partir dos contextos concretos em que os juristas atuam. Por isso, como fora mencionado, a contraposição entre o direito e a jurisprudência é significativa para uma reflexão deleuzeana sobre o direito (MUSSAWIR, 2011, p. 159-160).

Essa dualidade reflete uma atuação própria do campo jurídico que precisa, de início, ser pensado em sua especificidade, portanto, dissociado da política, da economia e de outros campos dos saberes: é preciso situá-lo ante a criatividade específica do jurídico, aqui pensado por meio da jurisprudência, para depois mapear o seu entrelaçamento com o que lhe é exterior.

Um aspecto importante desse potencial consiste em observar como a sociedade não converge para os diversos esquemas majoritários, expondo antes múltiplos processos de variação cujos resultados e implicações não podem ser integralmente mapeados de antemão. O entendimento tradicional sobre a democracia a associa com a formação de consensos como forma de composição da soberania popular: conceitos como vontade majoritária ou geral, no desdobramento histórico da filosofia política, tendem a expressar uma ideia de coletivo como majoritário enquanto o minoritário remete negativamente às elites (PATTON, 2005, p. 402 et seq.). O seu fundamento já estaria comprometido com o majoritário, a princípio sendo mais uma razão para opor a democracia à política minoritária tal como desenvolvida por Deleuze e Guattari.

É importante ressaltar que não existe, a rigor, uma oposição entre o majoritário e o minoritário (DELEUZE; GUATTARI, 2004, p. 85-86). O que se tem é um entrelaçamento entre dois processos distintos que mutuamente se influenciam: em um deles é mencionada composição de padrões que, no contexto das democracias liberais, é estabelecida mediante mecanismos jurídicos e deliberativos, enquanto o outro processo aponta para a inadequação - ou fuga - do social ante os seus padrões constitutivos (SCHUILENBURG, 2012, p. 116 et seq.). Ao associarem o devir ao minoritário, os autores insistem em destacar como os estratos mais rígidos não conseguem capturar plenamente as múltiplas formas de devires que marcam um determinado plano: a preocupação é voltada para os processos que compõem transformações significativas no social em vez de esclarecer as condições que levam à sua manutenção (PATTON, 2010, p. 137-138). 
Se existe um elemento a ser rejeitado neste ponto não seria o processo majoritário, uma vez que ele é indissociável do minoritário, mas o caráter exclusivamente representativo da política. Por isso a rejeição dos autores não leva à formulação de novos enunciados normativos os quais levariam a uma reconsideração do tipo de política representativa associada pelos autores ao processo de formação de uma vontade majoritária. Optam, ao contrário, por conceber novas formas em que grupos e indivíduos conseguem contestar e problematizar os standards majoritários em prol da criação de novas formas de vida.

A preocupação recai no potencial da política para a invenção e a proliferação de novas formas de vida e de relações sociais, o que está em sintonia com a estrutura normativa da política democrática. Em tese, mesmo uma concepção que identifica a democracia como forma de organização de governo, atribui o cerne do seu poder à potência criativa do demos. É nele, e não em qualquer princípio ou elemento transcendente, que se encontra o núcleo da criação incessante das instituições e arranjos sociais (GARO, 2008, p. 59 et seq.).

Uma democracia concebida através das lentes da imanência precisa considerar o seu fundamento como provisório e continuamente deslocado, levando a um déficit entre as suas diversas atualizações e o plano virtual cujos contornos e potencial escapam às atualizações. Os múltiplos devires minoritários pressionam e constroem zonas de experimentação que introduzem novos problemas e questões cujo impacto leva, por sua vez, a repensar as nuances e os limites do que se entende por democrático. São limitados, mas também capazes de subverter, os pressupostos filosóficos que moldam e limitam as democracias em suas atualizações:

\footnotetext{
Segue-se que a forma em que os Estados democráticos modernos surgem será parcialmente determinada pelas opiniões filosóficas que eles expressam. Neste sentido, as opiniões estabelecidas de uma determinada sociedade sobre o que é correto, justo, entre outros, vão limitar as atualizações institucionais e jurídicas dos ideais democráticos (PATTON, 2005, p. 411, tradução nossa) ${ }^{7}$.
}

Não se pretende que essas considerações venham servir de critério ou de elemento para construções normativas que almejem estabelecer como a democracia deveria ser organizada, quais seriam os seus limites e a melhor maneira de se partilhar os recursos simbólicos e materiais entre os membros da sociedade. Semelhante pretensão desconsideraria a dimensão virtual apresentada pelo conceito para se deter na sua atualização, além de limitá-lo a uma forma de governo.

\footnotetext{
${ }^{7}$ No original: "It follows that the form in which modern democratic states appear will be determined in part by the philosophical opinions that they express. In this manner, the considered opinions of a given society about what is right, fair, just and so on will constrain the institutional and legal actualization of democratic ideals”.
} 
O mais pertinente nessa abordagem consistiria em trazer para dentro da própria construção conceitual da democracia uma carga de experimentalismo e transgressão que a impediria de ser subsumida a qualquer técnica ou modo de administração política do social. Em outras palavras, conceber não tanto o democrático, mas aquilo que, pertencendo ao democrático, também sempre o desloca para além de si mesmo, transgredindo o estabelecido.

Desfazer a associação que vincula a democracia a uma forma específica de governo permite indagar pelo que existe de extemporâneo nesse conceito, ou seja, pelas sendas e veredas que os seus usos históricos apontaram, mas não exauriram. Trata-se de uma linha de argumentação um tanto quanto próxima àquela em que os autores remetem à obra de Pierre Clastres em torno das sociedades sem Estado: O Estado, ele mesmo, carrega em si uma exterioridade - a máquina de guerra - a que ele busca mobilizar em prol de sua própria conservação e segurança, ao mesmo tempo que precisa evitar que ela fuja ao seu controle, um risco sempre possível (DELEUZE; GUATTARI, 2008, p. 19).

Situar o virtual no democrático faz com que se possa observar de que maneira os acontecimentos presentes alteram as possibilidades situadas na relação entre formas de vida e imaginário democrático: quais formas de viver em sociedade permanecem latentes, impensadas, mas ainda assim presentes? Eventos trazem consigo também uma quantidade de questões e problemas que, por sua vez, modificam os múltiplos panoramas em que o democrático será atualizado. Cada obstáculo incorpora, por sua vez, a perspectiva de novos espaços de criação e de fuga, seja na ponderação de novos direitos e instituições, ou mesmo na construção de novas estratégias de enfrentamento político (OLIVIER, 2014, p. 7 et seq.).

\section{CONCLUSÃO}

Seria um tanto quanto precipitado considerar a democracia como um problema ou um aspecto de grande importância no panorama geral da filosofia deleuzeana, principalmente pela pouca preocupação que o autor demonstrou em discorrer sobre a temática ao longo de sua extensa obra. A preocupação central deste artigo consistiu em ressaltar que existem aspectos concernentes à filosofia do autor que podem ser frutíferos para se considerar uma concepção de democracia que não a esgota em forma de governo ou administração do poder político, sendo possível pensá-la para além da técnica e da normatividade do poder, rumo a formas de utopia que não se encontram ancoradas em outros planos.

Situar a democracia a partir da imanência envolve realizar algumas manobras teóricas de grande importância para o desenvolvimento deste trabalho. De início, observar como a sua dinâmica 
é autorreferencial, dispensando qualquer limitação a priori no tocante à maneira como o demos, enquanto sujeito coletivo, produz e reconstrói as múltiplas formas de vida que compõem a comunidade. Em seguida tratou-se de posicionar o demos como um centro imanente da democracia para, com isso, evitar qualquer referência a um fundamento que seja transcendente às próprias práticas, as quais formam e compõem um determinado arranjo democrático.

Se, por um lado, evitou-se recorrer a uma fundamentação transcendente como mecanismo de sustentação do regime democrático, por outro trata-se de um artifício teórico que permanece pouco elucidativo em termos de apontar as múltiplas possibilidades pertencentes ao conceito de democracia para transformar e subverter arranjos sociais específicos. Por isso se recorreu ao par atual/virtual com o intuito de pôr em evidência as múltiplas linhas de fuga que se abrem nos espaços democráticos: os vários regimes democráticos existentes, especialmente compreendidos enquanto formas de regimes políticos, são atualizações de uma democracia-virtual em constante transformação e cujas configurações podem ser redefinidas a cada atualização.

Tendo em vista as linhas gerais da presente pesquisa, um dos principais elos entre jurisprudência e democracia neste trabalho consistiu no caráter circunstancial, aberto e imanente compartilhado entre ambos os conceitos. A opção deleuzeana pela jurisprudência em detrimento do direito, sendo este associado pelo autor a uma normatividade geral e ampla, justifica-se, em parte, como forma de rejeição da transcendência; portanto, de modalidades normativas dissociadas das circunstâncias concretas as quais ela é mobilizada.

A inventividade da jurisprudência estaria intimamente associada às intervenções específicas sobre problemas que, por sua vez, exigiriam a construção de novas categorias e/ou a mobilização de normas jurídicas em contextos distintos, necessitando também de alguma forma de criatividade no tocante à articulação entre o caráter geral das normas jurídicas positivas e à questão suscitada pelo caso. Ademais, o enquadramento do problema jurídico, quer dizer, a seleção dos elementos e detalhes de uma situação concreta que são juridicamente pertinentes é já também uma expressão da criatividade: esses problemas precisam ser continuamente construídos, eles não chegam acabados às cortes.

A democracia se articularia com o conceito de jurisprudência concebida a partir da filosofia de Deleuze/Guattari ao menos em dois pontos: 1. trata-se de uma noção imanente da política; 2. promove a emergência de novas formas de vida social. No primeiro ponto, as noções e demandas políticas, discutidas e concretizadas no plano de fundo social, não são julgadas tendo como base qualquer noção de normatividade que exceda a vivência política da democracia. Assim como na jurisprudência, a democracia é atravessada por variações contínuas sobre o mesmo plano: formas de 
vida consideradas politicamente - ou socialmente - perniciosas são substituídas e repensadas à luz de novas conjunturas sociais, o que implica a modificação - ou substituição - dessas formas. O importante é que os padrões normativos aos quais se recorre para se julgar uma forma de vida são elaborados na própria vivência política da democracia. Disso não segue uma dependência necessária da forma-Estado, mas a rejeição da submissão da política a algum princípio organizador que lhe seja transcendente.

No segundo ponto, jurisprudência e democracia impulsionam a emergência de novas formas de vida social. Em ambos os casos, embora seguindo lógicas diferentes, a jurisprudência e a democracia constituem o palco para a elaboração de novos conceitos que abrem espaço, por sua vez, para a redefinição de antigas práticas e formas de relação social. Atuando sobre casos particulares, os problemas suscitados pela jurisprudência permitem repensar as categorias jurídicas sedimentadas, explorando os diversos caminhos que se abrem a partir dos vários devires específicos do social. A democracia, em uma concepção estritamente imanente, também opera sobre circunstâncias concretas e particulares, proporcionando a contínua redefinição dos potenciais específicos de uma comunidade, proporcionando deste modo uma política que desafia os limites do pensável e do viável em prol de experiências políticas por vezes inusitadas e desestabilizadoras do status quo.

Embora distintas, jurisprudência e democracia permitem formas de criação capazes de trazer à tona o potencial inexplorado subjacente às relações sociais e às instituições políticas estabelecidas. Seguindo lógicas específicas, propõem formas de problematização da ordem vigente e ressaltam as múltiplas linhas de fuga que se fazem presentes na constituição do social.

Desenvolver analiticamente a distinção virtual/atual é importante para ressaltar que as democracias empiricamente situadas compreendem apenas uma parcela limitada das possibilidades inscritas em seu domínio virtual. Não se sabe quais são os limites e as possibilidades do conceito de democracia para as diversas configurações do político. Por isso a insistência em evitar que ele seja subsumido a uma concepção operacional de política.

Permanecem ainda um tanto quanto imprecisas as múltiplas maneiras pelas quais as filosofias de Deleuze e de Guattari poderiam contribuir de maneira significativa, e até inovadora, para os atuais debates nos campos da filosofia política e do direito. A pretensão desta pesquisa foi a de apontar alguns elementos presentes na obra dos autores para mostrar que, a partir de uma certa leitura, talvez sirvam de subsídios para novas indagações naqueles dois campos e possam contribuir para novas abordagens referentes ao assunto. 


\section{REFERÊNCIAS}

CHESTERMAN, Simon. Violence in the name of human rights. In: DOUZINAS, Costas; GEARTY, Conor. The Cambridge Companion to Human Rights Law. Cambridge: Cambridge University Press, 2012.

COLEBROOK, Claire. Legal Theory after Deleuze. In: BRAIDOTTI, Rosi; COLEBROOK, Claire; HANAFIN, Patrick. Deleuze and Law: Forensic Futures. Basingstoke: Palgrave Macmillan, 2009, p. 6-23.

COLEBROOK, Claire. Pragmatic Rights. Law and Critique, v. 26, p. 155-171, 2015.

DELEUZE, Gilles. Negotiations. Columbia: Columbia University Press, 1995.

DELEUZE, Gilles; GUATTARI, Félix. Mil Platôs, v. 3. São Paulo: Editora 34, 2004.

DELEUZE, Gilles; GUATTARI, Félix. Mil Platôs, v. 5. São Paulo: Editora 34, 2008.

DELEUZE, Gilles; GUATTARI, Félix. What is Philosophy? New York: Columbia University Press, 1994.

GARO, Isabelle. Molecular Revolutions: The Paradox of Politics in the Work of Gilles Deleuze. In: BUCHANAN, Ian; THOBURN, Nicholas. Deleuze and Politics. Edinburgh: Edinburgh University Press, 2008, p. 54-73.

LEFEBVRE, Alexandre. Human Rights in Deleuze and Bergson's Later Philosophy. In: SUTTER, Laurent de; MCGEE, Kyle. Deleuze and Law. Edinburgh: Edinburgh University Press, 2012, p. 4868.

LEFEBVRE, Alexandre. The Image of Law: Deleuze, Bergson, Spinoza. Stanford, California: Stanford University Press, 2008.

MENGUE, Philippe. Deleuze et la question de la démocratie. Paris: L’Harmattan, 2003.

MUSSAWIR, Edward. Jurisdiction in Deleuze: The Expression and Representation of Law. London: Routledge, 2011.

OLIVIER, Bert. Signs of Radical Democracy - Deleuze, Badiou, Rancière and Tahrir Square. Theoria, v. 61, n. 2, junho/2014, p. 1-21.

PATTON, Paul. Deleuze and Democracy. Contemporary Political Theory, v. 4, 2005, p. 400-413.

PATTON, Paul. Deleuzian Concepts: Philosophy, Colonization, Politics. Stanford: Stanford University Press, 2010.

RANCIÈRE, Jacques. Disagreement: Politics and Philosophy. Minneapolis: University of Minnesota Press, 1999. 
SCHUILENBURG, Marc. Institutions and Interactions: On the Problem of the Molecular and Molar. In: SUTTER, Laurent de; MCGEE, Kyle. Deleuze and Law. Edinburgh: Edinburgh University Press, 2012. p. 111-131.

Leonardo Monteiro Crespo de Almeida Doutor e Mestre em Direito e Bacharel em Filosofia pela Faculdade de Direito do Recife/UFPE.E-mail: leonardoalmeida326@gmail.com 